\title{
O PRINCÍPIO DEMOCRÁTICO E CONSTITUCIONAL DA DIGNIDADE DA PESSOA HUMANA E A EXISTÊNCIA DO PROGRAMA BOLSA-FAMÍLIA: APONTAMENTOS SOBRE DIREITOS ELEMENTARES DOS CIDADÃOS DE BAIXA RENDA
}

\author{
Clóvis Roberto Zimmermann ${ }^{1}$
}

\section{RESUMO}

O objetivo desse artigo é tecer considerações sobre o princípio da dignidade da pessoa humana, determinado pelo artigo 1, inciso III, da Constituição da Republica Federativa do Brasil de 1988 e o processo de implementação do Bolsa Família. Melhor dizendo, o artigo visa analisar até que ponto o Programa Bolsa Família consegue atender ao princípio da dignidade da pessoa humana face às disparidades sociais do nosso país.

Palavras-chave: Bolsa família. Dignidade Humana. Políticas sociais.

\section{INTRODUÇÃO}

Quaisquer altemativas e políticas implementadas pelo Estado no sentido de propiciar melhores condições de vida a hipossuficiência dos cidadãos de baixa renda, inevitavelmente devem respeitar ao consagrado princípio da dignidade da pessoa humana, determinado pelo artigo 1, inciso III, da Constituição da Republica Federativa do Brasil de 1988.

O referido princípio, consolidado como um dos baluartes do Estado Democrático de Direito pátrio, apresenta-se intimamente vinculado aos direitos básicos e personalíssimos devidos a todos os cidadãos, seja de ordem moral, no cultivo do respeito e da urbanidade entre as pessoas, seja na garantia da subsistência, como o pleno acesso à educação, aos eficazes sistemas de saúde, a uma alimentação digna, dentre outros de importância similar.

Alexandre de Moraes, a respeito, sabiamente assevera que:

\begin{abstract}
A dignidade é um valor espiritual e moral inerente a pessoa, que se manifesta singularmente na autodeterminação consciente e responsável da própria vida e que traz consigo a pretensão ao respeito por parte das demais pessoas, constituindo-se um mínimo invulnerável que todo estatuto jurídico deve assegurar, de modo que, somente excepcionalmente, possam ser feitas limitações ao exercício dos direitos fundamentais, mas sempre sem menosprezar a necessária estima que merecem todas as pessoas enquanto seres humanos. $O$ direito a vida privada, a intimidade, a honra, a imagem, dentre outros, aparecem como conseqüência imediata da consagração da dignidade da pessoa humana como fundamento da Republica Federativa do Brasil'.
\end{abstract}

No que se refere à aplicação do princípio mencionado, importa ressaltar que todos os órgãos públicos e toda a atividade estatal devem 
obrigatoriamente se dirigir ao seu cumprimento, no cotidiano das suas atividades ou na propositura de medidas - a partir dos governos - em prol da sociedade, conforme se depreenderá do estudo sobre o Bolsa Família.

Neste prisma, o Estado tem o escopo de proteção e respeito, vendo-se compelido, via de conseqüência, a deixar de praticar atos na esfera individual que contrariem a dignidade da pessoa humana e tendo ainda o dever de protegê-la contra agressões de terceiros. Em suma, toda e qualquer ação do ente estatal deve ser avaliada sob pena de ficar-lhe caracterizada a inconstitucionalidade e de violar a dignidade da pessoa humana.

Não obstante a enorme abrangência do principio da dignidade da pessoa humana, desfaz-se a idéia de que seja um principio absoluto, já que dependerá da constatação, sob quais circunstancias, pode ser ameaçada a dignidade humana, num caso concreto. Todavia, resta-Ihe intocável o caráter de metaprincípio. A dignidade humana, composta pelo tripé - vida, liberdade e igualdade -, constitui, pois, valor unificador de todos os direitos fundamentais e tem ainda função de legitimar o reconhecimento de direitos fundamentais implícitos.

No tocante a realidade brasileira, tem-se que a indispensável dignidade nem sempre alcança as grandes parcelas da população, especialmente as menos favorecidas. Historicamente, as políticas desencadeadas pelos Governos Federais, notadamente no combate a pobreza, a miséria, ao analfabetismo e em prol de um sistema de saúde mais acessível, em muitas ocasiões não atingem a um grau de incontestável eficiência e eficácia, esbarrando em entraves econômicos, geográficos, sociais e, principalmente, políticos, que dificultam sobremaneira a sua consecução.

Não parece ser casual o fato de que políticas públicas vitoriosas como a implementação do Bolsa Família em âmbito brasileiro são, de fato, infelizmente, isoladas e esporádicas, posto que atender ao princípio da dignidade da pessoa humana jamais consistiu em tarefa simples, face as disparidades sociais do nosso país.

\section{A IMPLEMENTAÇÃO DO BOLSA FAMÍLIA ENQUANTO POLÍTICA SOCIAL EM PROL DA GARANTIA DO PRINCIPIO DA DIGNIDADE DA PESSOA HUMANA}

Parece não existir dúvidas de que o princípio da dignidade da pessoa humana, não obstante esteja longe de ser plenamente respeitado, alcançou grande reconhecimento com a implementação do Bolsa Família, em 20 de outubro de 2003, pelo Govemo do Presidente Lula, consistindo aquele num programa bem focalizado e com baixo custo para a nação (cerca de $0,4 \%$ do PIB), e que tem contribuído para a redução da pobreza e desigualdades. Destaca-se, ainda, seu forte impacto na melhoria da alimentação, no combate à desnutrição infantil e na permanência das crianças na escola.

Deve-se destacar a importância do Programa Bolsa Escola, implementado pelo Governo FHC, que tratava da concessão dos benefícios desde que houvesse a contrapartida dos beneficiários, qual seja, a efetivação da matrícula das crianças em escolas públicas. A destinação do Bolsa Família 
apresenta exigências parelhas, embora vise a um alcance mais elevado e dificil - posto que visa erradicar a fome, a miséria e a pobreza - o que não afasta aquilo o que Esping-Andersen ${ }^{3}$ chamara de solidariedade positiva e negativa. Ou seja, os conjuntos de direitos e expectativas dos indivíduos devem exigir grandes deveres e responsabilidades dos políticos em relação à comunidade.

Nesse esteio, o Bolsa Família alcança uma parcela da população, à qual o Estado devia e ainda deve muito em termos de políticas públicas adequadas. Tratava-se de cidadãos reiteradamente vitimados pela exclusão social ou com acesso limitado aos programas de transferência de renda e, por essa razão, apresentavam dificuldades em conseguir os elementos básicos para sua sobrevivência, como alimentação, vestuário e até mesmo material escolar. De fato, era necessário dar plena vazão a um programa social dessa envergadura, em concordância com o parecer de Franco:

\begin{abstract}
A focalização é o paradigma emergente, priorizando os mais necessitados em detrimento dos menos necessitados e daqueles que chegam primeiro. A população beneficiária, portanto, de forma dominante, é a classe média que consegue fazer pressão sobre o Estado e para a ampliação do mercado interno. Emerge a focalização dos mais necessitados, em situação de carência extrema, incapazes de solucionar de forma autônoma seus problemas. É dominante o enfoque das políticas centrado nos meios e não nos resultados e que estabelece como indicador de avaliação o gasto público. Emerge a preocupação centrada nos fins, nos impactos das políticas sobre as condições de vida da população, estabelecendo os indicadores de resultados a partir dos programas específicos ${ }^{4}$.
\end{abstract}

Em recente pesquisa realizada na região do semi-árido brasileiro, uma das regiões mais pobres do mundo, constatou-se uma redução significativa da desnutrição infantil. É possível afirmar, atualmente, que a criança incluída na faixa etária de seis a 11 meses de idade, que recebe o auxílio Bolsa Família, está relativamente protegida contra a desnutrição. Apenas esse resultado, por si só, já justificaria a existência do programa, que apresenta outros benefícios. Está comprovado que as crianças estão ficando mais na escola, o que lhes garantirá mais facilidades no ingresso ao mercado de trabalho.

A elevação da auto-estima das famílias beneficiadas pelo recurso financeiro também merece destaque, posto que a presença da mulher no grupo familiar ficou fortalecida à medida em que passou a controlar um rendimento revertido inteiramente para o lar. Com efeito, a mulher passa a ser mais respeitada perante o meio social, uma vez que, com a certeza e liquidez do auxílio, aquela adquire status de boa compradora perante o comércio, além de não assumir dívidas que não tenha condições de cumprir. Desta forma, as mulheres têm a sua auto-estima elevada no grupo familiar e social, o que apenas reforça o princípio da dignidade da pessoa, objeto central de nosso presente estudo.

Rômulo Paes, em brilhante artigo, assevera, ainda, que:

Aliado a isso, o Bolsa Família dinamiza o comércio, principalmente nas regiões mais pobres. Nos municípios muito pequenos, abaixo de 20 mil habitantes, com predomínio da população rural, o impacto é enorme na economia local. Outro aspecto, que julgo mais importante, é que a sociedade fica melhor quando se reduz a 
pobreza e a desigualdade. Há possibilidade de o Brasil se desenvolver mais porque teremos trabalhadores mais qualificados. Uma sociedade mais justa, mais equânime, é melhor para todos ${ }^{5}$.

No que tange à auto-estima dos cidadãos, é imprescindível vincular essa com o despertar de uma atitude mais pró-ativa dos mesmos em relação ao trabalho, evitando-se a dependência excessiva do recurso em comento. Nesse prisma, há quem associe, nem sempre com a necessária justiça, o recebimento do benefício à acomodação por parte dos seus beneficiários. A postura, como prova a extensa maioria dos casos analisados empiricamente, é equivocada se levarmos em conta que o valor do recurso do Bolsa Família, que varia, em junho de 2008, de $R \$ 20,00$ (dezoito reais) a $R \$ 122,00$ (cento e doze reais), de acordo com cada caso, tem caráter complementar e não concorre - nem de longe - com a renda do trabalho, ainda que informal.

Tem-se notado que o perfil das pessoas recebedoras do auxílio trabalham e - frise-se - trabalham desde cedo. Os chefes de família e demais membros, em idade preconizada para o trabalho, iniciam mais cedo e saem mais tarde do mercado porque, de fato, precisam trabalhar mais. Na verdade, a experiência do Bolsa Família reforça o conceito de que a população brasileira, em sua larga maioria, sabe usar com inteligência este tipo de benefício, numa demonstração de responsabilidade.

\section{PERFIL DOS BENEFICIÁRIOS DO BOLSA FAMÍLIA NO CONTEXTO DA POPULAÇÃO BRASILEIRA ENTRE 2005 E 2007: ANÁLISE DE DADOS EMPÍRICOS QUE ENFATIZAM A SUA IMPORTÂNCIA.}

O Programa Bolsa Família, em sua aplicabilidade, apenas acumula críticas quando incompreendidos seus objetivos, utilizados como pretextos para ataque gratuito aos governos ou desconhecidas as suas marcantes incidências sociais, representadas por dados incontestes advindos do Ministério do Desenvolvimento Social e Combate à Fome do Governo Luiz Inácio Lula da Silva e que, sem dúvidas, auxiliam na delineação do perfil daqueles que são beneficiados pela renda do Bolsa Família.

De cada cem famílias beneficiárias, por exemplo, 36 (trinta e seis) têm acesso à rede pública de esgoto e 66 (sessenta e seis) são atendidas pela coleta de lixo. A energia elétrica chega a $76 \%$ (setenta e seis por cento) das residências incluídas no programa de transferência condicionada de renda. As características sócio-econômicas da população de baixa renda estão no Perfil das Famílias Beneficiárias do Programa Bolsa Família, divulgado reiteradamente pelo Ministério do Desenvolvimento Social e Combate à Fome.

Caso façamos uma comparação entre as informações do Cadastro Único dos Programas Sociais - base de dados usada pelo Bolsa Família - com as das famílias mais pobres do Brasil, identificadas pela Pesquisa Nacional por Amostra de Domicílios (Pnad), vislumbraremos o acerto da transferência de renda para quem atende ao critério do programa ( $R$ \$120,00 per capita/mês).

Consoante se depreende dos estudos de cada estado e região do Brasil, chegou-se à conclusão de que o Bolsa Família tem uma boa focalização na 
população de baixa renda, mas alcançaria maior eficiência e eficácia se fosse unido a outras políticas públicas destinadas a esse segmento.

Quanto à situação educacional, mais de $\mathbf{8 0} \%$ das cerca de 11 milhões de pessoas responsáveis pelo recebimento do benefício estudaram até a $8^{\mathrm{a}}$ série do Ensino Médio, enquanto $16,2 \%$ se declararam analfabetas. A maior parte dos beneficiários - $69 \%$ (sessenta e nove por cento) - vive em áreas urbanas. É fundamental, portanto, que sejam envidados esforços pelos governos federal, estaduais e municipais para melhorar o acesso da população pobre a saneamento básico, a habitação e a escolaridade.

Não obstante a situação dos beneficiários demonstre precariedade no acesso aos serviços públicos, a comparação do perfil de 2005 com o de 2007 mostra que houve boa melhoria nesse período. 0 abastecimento de água pela rede pública atinge, atualmente, $64,7 \%$ das famílias beneficiadas, contra $61,1 \%$ em 2005. O acesso médio aos serviços de escoamento sanitário passou de $33,9 \%$ para $36,4 \%$ entre as famílias inscritas no programa.

São 45,8 milhões de pessoas atendidas com a transferência de benefícios, que hoje variam de $R \$ 20,00$ a $R \$ 122,00$. O objetivo extrínseco do Governo Federal ao enviar mais de 819,7 milhões/mês a essas famílias é erradicar a fome, a extrema pobreza e tentar reduzir as desigualdades sociais.

\section{O AUXÍlIO BOLSA FAMÍlIA AVALIADO POR OUTRO PRISMA CRÍTICO: ABORDAGEM SOBRE O EVENTUAL DESVIO DE FINALIDADE E UM ENFOQUE ACERCA DAS SUAS DESVANTAGENS.}

O programa Bolsa Família, como qualquer outra iniciativa governamental envolvido num caráter político, além da preocupação social, desperta críticas de todas as naturezas, e neste caso não há diferença. Considerado por muitos como "um programa que vicia" e que peca por não exigir contrapartidas das famílias, o Bolsa Família nos faz também refletir acerca da possibilidade de promoção do comodismo e do contentamento com a renda mínima. Perguntase: o referido auxílio erradica de fato a pobreza ou a mantém, amparada pela "acomodação" dos seus beneficiários?

Qualquer entendimento mais abalizado deverá nos reportar, a princípio, à conversão do Bolsa-Escola, criado no Governo FHC, ao atual Bolsa Família. No primeiro, destacava-se a vinculação do recebimento do benefício às famílias de baixa renda desde que houvesse a sua reciprocidade no sentido de que matriculassem seus filhos na escola. Ou seja, um modelo dotado de necessária clareza.

O desafio enfrentado pelo Governo Lula na sua audaz ampliação dos horizontes alcançados pelo benefício, com a conversão em Bolsa Família, foi e é justamente deixar incidir sobre o Programa a mesma clareza solar que iluminava o antecessor, já que com a mudança, sai de cena apenas o foco educacional do benefício, e advém o foco da obrigatoriedade da freqüência de postos de saúde. Essa fato originou críticas, como assinala Cristovam Buarque.

A Bolsa Família pode até diminuir a miséria entre os beneficiários, mas não elimina a pobreza do Brasil. Diminui a pobreza momentânea, mas não constrói um País rico, pois não reduz a 
dependência. Isso, só com uma revolução na educação. A BolsaEscola era parte dessa revolução. [...] a tragédia educacional permanece [...] porque ela inviabiliza o futuro, mas não reduz os índices de popularidade nem tira votos ${ }^{6}$.

Crítico ferrenho do Bolsa Família, que promoveu sérias mudanças em sua idéia original - o senador foi o idealizador do Bolsa Escola - Cristovam Buarque não é figura uníssona em seu parecer desfavorável ao beneficio em tela. Vejamos o que denota José Henrique Souza:

Fica claro que o 'Programa Bolsa Família', pelas próprias dimensões que tomou, pode se tornar mais uma forma de marketing eleitoral do que um 'Programa Social'. Talvez, também, venha a ser conhecido pelos críticos como um 'Programa de Equalização da Renda' baseado na estratégia da 'selic para os ricos e esmola para os pobres'. Programas como o "Bolsa Família" poderiam ser apenas emergenciais e temporários [...]. Um programa como o "Bolsa Família" seria necessário para países que sofrem com guerras, grandes contingentes de refugiados, catástrofes climáticas ou epidemias. Mesmo nesses casos tal programa deveria ser temporário e focado na obtenção da independência financeira dos beneficiados. Nada disso vem ocorrendo de fato. Nem o Brasil foi castigado por "tsunamis" ou furacões e nem os assistidos conseguem sair da humilhante situação de quem recebe uma esmola de pouco mais de $\mathrm{R} \$ 2,00$ por dia ${ }^{7}$.

Existe uma preocupação latente de que o Bolsa Família não se torne um programa permanente no governo brasileiro, figurando apenas como "um impulso temporário de oportunidades para os mais pobres". Programas similares seriam apenas necessários para países que sofrem com guerras, grandes contingentes de refugiados, catástrofes climáticas ou epidemias. Contudo, com a introdução Bolsa Família, o Estado brasileiro começa a adotar os passos que os países desenvolvidos seguiram no combate à fome e à miséria. Já em 1961, a Alemanha, por exemplo, criou um programa denominado auxílio social (Sozialhilfe), que mudou de nomenclatura em 2005 para Arbeitslosengeld II, o qual tem contribuído decisivamente para que nesse país não exista fome e miséria. Trata-se de uma transferência monetária de cerca de 700,00 Euros por pessoa, coberta pelo Estado, cujo tempo de duração é ilimitado, de modo que cerca de um terço da população alemã se favorece desse apoio financeiro em algum período da sua vida. Afirmar que programas similares deveriam apenas existir em épocas de guerras e situações similares, é desconhecer as políticas de países mais ricos e que conseguem resolver suas mazelas sociais.

Respeitáveis que sejam as críticas mencionadas, é preciso entender que - Bolsa Família, estando obviamente longe da perfeição, perfaz uma política pública ousada e que se faz necessária no contexto de grande miséria e pobreza existentes em nosso país, não sendo mera formalidade a admiração que países ricos há muito tempo ${ }^{8}$ e recentemente os emergentes de outros continentes têm demonstrado pelo programa social.

4 AS RELAÇÕES ENTRE O BENEFíCIO SOCIAL E A EFETIVA SATISFAÇÃO DOS DIREITOS HUMANOS - E SEUS RESPECTIVOS ENTRAVES. 
Reportando-nos ao princípio da dignidade da pessoa humana, anotado na Carta Magna de 1988, é digno de nota o privilégio a ser destinado aos direitos humanos em políticas públicas como o Bolsa Família - e que em alguns casos não existe. Não parece ser aceitável a noção de que a política pública não seja acompanhada, em todas as suas fases, pela sociedade civil, imediatamente interessada nos seus frutos. Reside a contradição no fato de que a sociedade participa de forma indireta da consecução dessas políticas.

O Comentário Geral $n^{\circ} 12$, desenvolvido pelo Comitê de Direitos Econômicos, Sociais e Culturais do Alto Comissariado de Direitos Humanos das Nações Unidas, exige que a implementação das políticas públicas voltadas à garantia do direito à alimentação passe obrigatoriamente pela obediência a princípios elementares como a transparência, a participação popular e a descentralização política, conforme vemos a seguir.

A formulação e a implementação das estratégias nacionais para o direito à alimentação requerem obediência total aos princípios de responsabilidade, transparência, participação, descentralização, capacidade legislativa e independência do judiciário?.

Depreende-se do texto que a participação da sociedade civil deve se estender desde o seu conhecimento da legislação atinente à espécie até a formulação das políticas públicas. Apenas por meio dessa integração entre cidadãos e Poder Público, naturalmente haverá possibilidades de se garantir a realização dos direitos humanos e, via de conseqüência, a satisfação das condições de vida de todos.

Nesse sentido, cumpre observar que o Bolsa Família, em atenção à garantia plena dos direitos humanos, apresenta uma incoerência que, de certa forma, o traz prejuízos, configurada na sua condicionalidade, ou seja, aquele cidadão que indubitavelmente é detentor de um direito não recebe o auxílio de maneira incondicional.

As famílias postulantes ao recebimento do benefício não o percebem apenas porque passam por necessidades básicas ou porque preenchem os requisitos exigidos pelo Governo Federal. É necessário que os municípios realizem uma triagem e determinem um número máximo de famílias contempladas que, uma vez preenchido, excluirá outras tantas, muitas em casos de miserabilidade idêntica àquelas beneficiadas pelo Bolsa Família ${ }^{10}$.

O ônus suportado pelo Bolsa Família, não obstante suas diversas boas conseqüências, é o fato de sua concessão não ser exatamente direcionada a idéia de que todos os necessitados o receberão. No entender abalizado de Zimmermann", o Bolsa Família "adota, ao contrário, uma seletividade por vezes excludente", além de afirmar que sua lógica '[...] está fundamentada no discurso humanitário da ajuda e da assistência ao invés de provimento de direitos".

Se se direcionasse mais ao estado de vulnerabilidade das famílias e menos ao caráter temporário do acesso ao benefício, o Bolsa Família, sem sombra de dúvidas, alcançaria maior maturidade em suas pretensões. Vulnerabilidade, em termos compreensíveis, não significa necessariamente sujeição à fome, mas a uma gama de mazelas sociais. Essa é a universalidade 
a ser melhor interpretada - e nem sempre eficazmente atacada - pelo benefício Bolsa Família. Nesse contexto, adquire grande importância a implementação pelo presidente Lula, por intermédio da Lei $n^{0} 10.835 / 2004$, da denominada renda básica de cidadania, consoante veremos a seguir.

\section{A IMPLEMENTAÇÃO DA RENDA BÁSICA DE CIDADANIA COMO EVOLUÇÃO DO PROGRAMA BOLSA FAMÍLIA}

A instituição da renda básica de cidadania configura uma clara evolução na ótica das políticas públicas brasileiras, pois se trata de fazer valer oficialmente uma renda básica universal para todos os cidadãos do país. A legislação aponta que o valor deve ser bastante para cobrir as despesas mínimas com alimentação, educação e saúde, além de estabelecer que todos os cidadãos brasileiros, sem qualquer distinção, têm direito ao recebimento de um benefício monetário equânime a todos.

$\mathrm{Na}$ realidade, a aludida inovação não reside na definição da imparcialidade da destinação dos recursos e sim na sua incondicionalidade. Merece aplausos a promulgação da Lei posto que clareia as relações, por vezes obscuras, entre políticas públicas e o homenageado princípio da dignidade da pessoa humana, no sentido de que não discute a titularidade de um direito, mas cumpre-o.

Vejamos o que contempla um dos responsáveis pela instituição da renda mínima no Brasil, o senador Eduardo Matarazzo Suplicy:

A sanção da lei é um passo notável para os brasileiros e um exemplo para a humanidade. $O$ presidente Lula está dando um passo importantíssimo para a realização dos anseios do povo, com racionalidade, para atingir os objetivos de erradicar a pobreza ${ }^{12}$.

Philippe Van Parijs (2004) filósofo e economista belga, uma das maiores autoridades em renda mínima no mundo, assevera que:

\footnotetext{
Diferentemente dos programas de bem-estar exclusivamente voltados para os pobres, a Renda Básica de Cidadania contém o compromisso, quando inteiramente implantada, de atacar a pobreza sem criar dependência, de garantir a todos a subsistência diária sem estigmatizar o pobre, sem criar uma amadilha que os exclui do mercado de trabalho ${ }^{13}$.
}

A renda básica de cidadania deveria, a partir de 2005, gradualmente modificar a atuação do Bolsa Família, superando as condicionalidades e expandindo-se para as camadas mais pobres da população brasileira. Sua inteira vinculação com a dignidade da pessoa humana não pode ser ignorada, pois oferece ao cidadão a liberdade de escolher e de evitar a fome, bem como libertá-los absolutamente da sujeição a condições de trabalho degradantes a sua personalidade e, por conseguinte, permitindo que seu poder de escolha possa ser direcionado apenas a trabalhos que elevem sua moral e auto-estima.

Nesse sentido, Zimmermann e Silva, em oportuna referência a Van Parijs, ponderam que: 
A própria natureza incondicional da Renda Básica é uma vantagem, pois possibilita a disseminação de poder de barganha de modo a capacitar os menos favorecidos a distinguir entre empregos atraentes ou promissores e empregos desagradáveis ${ }^{14}$.

Ou seja, é de grande valia a instauração do referido Programa de Renda Básica de Cidadania posto que, ao desenhar-se como melhor política pública do que o Bolsa Família, caminha em sua direção oposta ao deixar de lado as condicionalidades, as exigências e as regras excessivas de concessão de benefício, relevando - e isso é o que de fato importa - a condição essencial de ser humano, que por si só, autoriza e justifica a idealização e consecução de uma política pública satisfatória.

\section{CONSIDERAÇÕES ATUAIS SOBRE O PROGRAMA BOLSA} FAMÍLIA: QUALIDADE DE VIDA VERSUS INSEGURANÇA ALIMENTAR, REAJUSTE A PARTIR DE JULHO/2008 E REFLEXOS DA CRISE MUNDIAL DOS ALIMENTOS.

Recente pesquisa desenvolvida pelo Instituto Brasileiro de Análises Sociais e Econômicas - IBASE - apontou para uma dualidade na aplicação do Programa Bolsa Família aos cidadãos brasileiros. Se por um lado $87 \%$ de um contingente de cinco mil titulares do cartão questionados afirmaram que 0 emprego do auxílio financeiro se direciona à compra de alimentos, o que atende aos anseios diretos do governo Lula, por outro percebeu-se a existência de uma insegurança alimentar, mesmo com a injeção de recursos entre as famílias mais carentes.

No primeiro caso, depreende-se da pesquisa que tanto a qualidade quanto a variedade dos alimentos consumidos por essas famílias aumentou, 0 que sem dúvida configura um extremo avanço na referente política governamental. $O$ contraponto, porém, reside na insegurança demonstrada pelos cidadãos entrevistados quanto ao que se possa esperar de uma continuidade regular da alimentação.

É que, consoante a pesquisa realizada pelo instituto citado, $83 \%$ dos titulares revelaram se enquadrar nos três níveis que caracterizam a insegurança alimentar: grave, moderada e leve. A insegurança grave se desenha nas situações em que 0 individuo, apesar do recebimento do benefício, está inserido em um contexto de pobreza por demais amplo, que não o livra de se sujeitar à fome. A insegurança moderada consiste na cautela em se reduzir o número de alimentos a serem adquiridos, posto que há o fundado receio de que faltem aqueles. Por sua vez, a insegurança leve está configurada no temor de que, em futuro próximo, não haja rigorosamente nada para se comer.

Por esse prisma, é forçoso salientar que, sob a ótica das políticas públicas, a pesquisa mostrou que o Bolsa Família ainda não é completamente eficaz, simplesmente porque não garante absoluta segurança alimentar, não obstante seja fundamental para melhorar a alimentação $e$, via de conseqüência, a qualidade de vida dos cidadãos mais carentes.

Munido desse importante referencial científico, o Governo Federal ocupou-se em proceder a reajuste no benefício, elevando-o, no valor mínimo, 
de 18,00 a 20,00 reais e, no valor máximo de até 172,00 reais, ou seja, alteração significativa no percentual de $8 \%$ naquele que é o programa carrochefe do Governo do Presidente Lula.

Acertada, a nosso ver, a decisão do reajuste, posto que, respeitadas que sejam as críticas tecidas ao referido ato, para muitos, dotado de interesses eleitoreiros, é certo que a majoração dos índices se fazia necessária por uma razão muito mais discutível, a crise mundial dos alimentos que, especialmente neste primeiro semestre de 2008, alcançaram patamares muitos altos em todos os continentes. O Brasil é uma das nações mais afetadas, principalmente pelo fato de que alimentos básicos na preferência brasileira, como o arroz e o feijão, são os que mais sofreram reajuste.

Não restava ao Bolsa Família outra alternativa que não acompanhar a alta dos preços dos alimentos e, para tanto, se comportou com habilidade o Governo Federal na concessão do aumento do referido benefício. Contudo, comparado com muitos países europeus, o valor do Bolsa Família ainda é muito baixo para garantir o mínimo de subsistência aos cidadãos pobres brasileiros.

\section{CONCLUSÃO}

Em suma, tem-se que a satisfação dos direitos básicos à educação, saúde, alimentação, em especial, e outros devidos à população e protegidos pela Constituição Federal do Brasil, é sempre proporcional ao binômio estabelecido entre políticas públicas e compreensão exata da realidade nacional.

A dignidade da pessoa humana, enquanto lema constitucional, a partir do instante em que se vê intrínseca às políticas públicas, passa a defender justamente a garantia irrestrita de que a existência não signifique subsistência tampouco subserviência. Ao contrário, o princípio preconizado na Constituição e personalizado em políticas públicas bem intencionadas como o Programa Bolsa Família e a Renda Básica tem o condão de resgatar e assegurar os direitos humanos, enquanto direitos individuais e incondicionais.

O combate à miséria e à pobreza existentes em nosso país exigem, instantaneamente, que se abandonem as idéias pouco ousadas ou que atuem como meros sustentáculos de discursos eleitoreiros, sem efetividade e sem benefícios bastantes que avalizem 0 acesso ao necessário para as famílias pobres. Fundamental é agir com seriedade e paralelamente adquirir consciência acerca da gradação de um projeto bem-sucedido, que não se torna exultante "do dia para a noite" no contexto pátrio.

O histórico desenvolvido pelas políticas públicas brasileiras, com destaque para o Bolsa Escola e mais recentemente o Bolsa Família, merecem o devido reconhecimento, desde que se reconheça também a sua carência permanente de evolução, com maior participação dos atores sociais, maior transparência dos agentes públicos, especialmente dos municípios e melhor direcionamento para as camadas mais pobres, verdadeiras interessadas nos seus mais eficientes resultados. Não é qualquer iniciativa governamental, por melhor intencionada que seja, que consegue beneficiar 11,1 milhões de 
famílias, razão porque será sempre louvável realçar os resultados do Programa Bolsa Família, uma das mais consistentes contribuições do Estado brasileiro à erradicação da pobreza e à preservação do princípio da dignidade da pessoa humana, homenageado pela Constituição da República Federativa do Brasil.

\section{THE HUMAN CONSTITUTIONAL AND DEMOCRATIC DIGNITY PRINCIPLE AND FAMILY AID BENEFIT: ELEMENTARY WRITINGS ABOUT BASIC RIGHTS OF LOW INCOME HOUSEHOLDS}

\section{ABSTRACT}

This article objective is considerate the human dignity principle, established by the article 1, incise III, of the 1988's Constitution of Republican Federation of Brazil and the process of implementation of the Family Aid Benefit. Better said, the article aims to evaluate if the Family Aid Benefit fulfills the role of materializing the human dignity principle in face of country's social disparities.

Keywords: human dignity, social policies, family aid benefit

\section{NOTAS}

Doutor em Sociologia pela Universitat Heidelberg (Ruprecht-Karls), Alemanha. Professor de Ciência Política da Universidade Federal do Recôncavo da Bahia.

2 MORAES, Alexandre de. Direitos Humanos e Fundamentais, p. 60.

3 ESPING-ANDERSEN, Gosta. As três economias políticas do 'Welfare State. Lua Nova, São Paulo, n. 24, p. 85-116, 1991.

4 FRANCO, Rolando. Los paradigmas de la política social en América Latina. Revista de La CEPAL, Santiago, n. 58, p. 9-22, abr.1996.

5 PAES, Rômulo. Bolsa-Família: necessário e justo. www.fomezero.gov.brlartigo/bolsafamilia-necessario-e-justo-romulo-paes. 2006

6 BUARQUE, Cristovam. http://www.cristovam.com. br/index.php?secao=secoes. php\&sc=8\&id=4513

7 SOUZA, José Henrique. $O$ Bolsa-Família mantém ou erradica a pobreza?. http://www.jornaldedebates.ig.com.br/index.aspx?cnt id=15\&art id=11834.

8 A exemplo de comparação, o Reino Unido introduziu programas de transferência de renda em 1948, Finlândia em 1956, Suécia 1957, Alemanha 1961, Áustria 1974 e França em 1988.

9 Comitê de Direitos Econômicos, Sociais e Culturais do Alto Comissariado de Direitos Humanos das Nações Unidas/ONU. Comentário Geral número 12 - 0 direito humano à alimentação (art. 11), Genebra: ONU, 1999, artigo 25.

10 Em dezembro de 2007, 11.129.327 milhões de pessoas eram beneficiárias do Bolsa Família. Por outro lado, segundo informações do sítio do Ministério do Desenvolvimento Social, em dezembro de 2007 havia 15.159.855 milhões de famílias inscritas no Cadastro Único com renda per capita inferior a $R \$ 120,00$, ou seja, famílias que cumpriam os requisitos de elegibilidade do Programa. Isto significa que 4.030.528 milhões de famílias não estavam sendo incluídas, embora se enquadrem nos critérios de elegibilidade do Programa.

11 ZIMMERMANN, Clóvis Roberto. Os programas sociais sob a ótica dos direitos humanos: 0 caso do Bolsa Família do Governo Lula no Brasil. Revista Intemacional de Direitos Humanos. Número 4. Ano 3. 2006, p. 152.

12 SUPLICY, Eduardo Matarazzo. http://www1.folha.uol.com.br/folha/brasil/ult96u56992.shtml 
13 VAN PARIJS, Philippe. Trecho de documento lido na solenidade da promulgação da Lei 10.835/2004. Palácio do Planalto, 2004.

14 ZIMMERMANN, Clóvis Roberto. SILVA, Marina da Cruz. Novos desafios ao Programa Bolsa Família: a transição para a Renda Básica de Cidadania. Revista Espaço Acadêmico - no 76 - Setembro/2007 - Mensal - Ano VII

\section{REFERÊNCIAS}

BUARQUE, Cristovam. Artigos. Idéias para mudar o país. Foram avisados Revista Isto É - 24/09/2007

http://www.cristovam.com.br/index.php?secao=secoes. php\&sc $=8 \&$ id $=4513$

COMITÊ DE DIREITOS ECONÔMICOS, SOCIAIS E CULTURAIS DO ALTO COMISSARIADO DE DIREITOS HUMANOS DAS NAÇÕES UNIDAS/ONU. Comentário Geral número 12 - 0 direito humano à alimentação (art. 11), Genebra: ONU, 1999, artigo 25.

ESPING-ANDERSEN, Gosta. As três economias políticas do 'Welfare State". Lua Nova, São Paulo, n. 24, p. 85-116, 1991.

FRANCO, Rolando. Los paradigmas de la política social en América Latina. Revista de La CEPAL, Santiago, n. 58, abr.1996, p. 9-22.

MEDEIROS, Marcelo; BRITTO, Tatiana; SOARES, Fábio. Programas focalizados de transferência de renda no Brasil: contribuições para o debate. In: TEXTO PARA DISCUSSÃO No 1283. Rio de Janeiro, IPEA, p. 5-33.

MORAES, Alexandre de. Direitos Humanos e Fundamentais. p. 60.

PAES, Rômulo. Bolsa-Família: necessário e justo. www.fomezero.gov.br/artigo/bolsa-familia-necessario-e-justo-romulo-paes. 2006

SOUZA, José Henrique. $O$ Bolsa-Familia mantém ou erradica a pobreza?. http://www.jornaldedebates.ig.com.br/index.aspx?cnt id=15\&art id=11834

SUPLICY, Eduardo Matarazzo.

http://www1.folha.uol.com.br/folha/brasil/ult96u56992.shtml

VAN PARIJS, Philippe. Trecho de documento lido na solenidade da promulgação da Lei10.835/2004. Palácio do Planalto, 2004

ZIMMERMANN, Clóvis Roberto. Os programas sociais sob a ótica dos direitos humanos: o caso do Bolsa Família do Governo Lula no Brasil. Revista Internacional de Direitos Humanos. Número 4. Ano 3. 2006, p. 145-156

ZIMMERMANN, Clóvis Roberto. SILVA, Marina da Cruz. Novos desafios ao Programa Bolsa Família: a transição para a Renda Básica de Cidadania. Revista Eletrônica Espaço Acadêmico - $n^{\circ} 76$ - Setembro/2007 - Mensal Ano VII. 
Recebido em: para publicação 17/03/2009

Aceiro para publicação 19/12/2009 